\title{
Microbial biomass as an antioxidant for tilapia feed
}

\author{
Thiago Luís Magnani Grassi; Dayse Lícia Oliveira, Natalia Mingues Paiva; \\ Juliana Campos Pereira Diniz; Anelise Maria Bosco; Ariana Aparecida Ferreira Pereira; \\ Amanda Regina Pinatti Menezes; Taiana Carvalho Valadares; \\ Rosemeire Conceiçao Parra Pastor; Paulo César Ciarlini; Giovani Sampaio Gonçalves; \\ Morris Villarroel; Elisa Helena Giglio Ponsano
}

\begin{abstract}
Microbial biomass (MB) produced by different industries is thought to be a benefi-cial supplement in fish feed due to high contents of antioxidants and pigments. However, little is known about their impact on fish health. In this experiment, 960 tilapia (26.84 $\pm 1.03 \mathrm{~g}$ ) were fed one of eight experimental diets - a control diet with no $M B(C)$, a control diet with vitamin $E$ (VE) and six diets with three types of MB at two concentrations (0.25\% and 0.5\%): Rubrivivax gelatinosus (RG25 and RG50), Spirulina platensis (SP25 and SP50) and Saccharomyces cerevisiae (SC25 and SC50). Adding MB to diets decreased plasma total oxidant status, malonaldehyde and leucocyte respiratory burst; increased the total antioxidant status; and did not affect the blood biochemical parameters. In flesh, the use of the $\mathrm{MB}$ lowered the thiobarbituric acid-reactive substances and increased redness (except for SC) and carotenoid deposition (except SC25). So, it was concluded that the use of the MB provided an antioxidant effect in tilapia blood plasma, decreased lipid oxidation and increased pigmentation and carotenoid deposition in the fish flesh, without impart-ing a negative impact on the animals' health.
\end{abstract}

KEYWORDS

biochemical analysis, carotenoids, colour, leucocyte respiratory burst, lipid oxidation, TBARS

\section{1 | INTRODUCTION}

Microbial biomass (MB) generated by biotechnological processes can be used to supplement fish feed (Grassi et al., 2016; Jaime-Ceballos, Hern'andez-Llamas, Garcia-Galiano, \& Villarreal, 2006; Reque, Moraes, Belo, \& Moraes, 2010), which helps to reduce costs and lessen environmental impacts, but few studies have considered the antioxidant potential of MB in tilapia (Herath, Haga, \& Shuichi, 2016; LaraFlores, Olvera-Novoa, Guzm 'an-M'endez, \& L'opez-Madrid, 2003). Two important $\mathrm{MB}$ with antioxidant effects currently produced in large quantities include Saccharomyces cerevisiae, a yeast used to elaborate many products (e.g. ethanol production) and that is nor-mally discarded, and Spirulina (Arthrospira) platensis, a blue-green microalgae that can be produced in wastewater (Chang, Wu, Bian, Feng, \& Leung, 2013). In addition, a relatively new candidate for fish is Rubrivivax gelatinosus (previously named Rhodocyclus gelatinosus), a phototrophic bacterium produced in pasteurized wastewaters of fish slaughterhouse (Lima, Ponsano, \& Pinto, 2011; Ponsano, Lacava, \& Pinto, 2003) that has already been used for other animals raising (Ponsano, Pinto, Garcia Neto, \& Lacava, 2002, 2004).

Dietary antioxidants as the included in the above MB (e.g. carotenoids) help to maintain an equilibrium in the formation and control of reactive oxygen species, which in turn help improve growth performance, resistance to stress and disease and survival of cultivated fish and shrimp (Hamre et al., 2004). Adding MB supplements with a high antioxidant potential to fish feeds can also help to substitute 
synthetic products (e.g. BHT and vitamin E, the most used in tilapia feed; see Bhosale, 2004; Bhosale \& Bernstein, 2005; Stahl \& Sies, 2003), which may pose health risks for fish and consumers (Anesini, Ferraro, \& Filip, 2006; Hou, 2003; Prior, 2004). In a more specific manner, Spirulina platensis is regarded as a cheap and rich source of antioxidant pigments such as carotenoids and phycocyanin (JaimeCeballos et al., 2006; Li, Guo, \& Li, 2003; Morist, Montesimos, Cusido, \& Godia, 2001), with effects on humoral and cellular immunity (Takeuchi, Lu, Yoshizaki, \& Satoh, 2002). Saccharomyces cerevisiae is a rich source of antioxidants such as vitamins and peptides, which increases growth, stimulates the innate immune system and improves fillet quality (Ran et al., 2015; Reque et al., 2010; Rodriguez, Cuesta, Ortuno, Esteban, \& Meseguer, 2003). Rubrivivax gelatinosus contains oxycarotenoids (xanthophylls), a group of caro tenoids with antioxidant potential that also provide pigmentation through selective deposition on different animal tissues (Baker, Pfeiffer, Schöner, \& Smith-Lemmon, 2002; Ponsano, Paulino, \& Pinto, 2008). According to Grassi et al. (2016), using up to $0.14 \%$ R. gelatinosus in tilapia feed increases protein retention and redness on the fillets but less is known about the potential effects of higher supplementation on fish health.

A high level of antioxidants in blood, indicated by high plasma total antioxidant status (TAS) and low plasma total oxidant status (TOS), as well as flesh with low TBARS (2-thiobarbituric acid-reactive substances), can help to increase tilapia health and preserve product quality during processing and storage, inhibiting lipid degradation by oxidation and thus increasing shelf life (Cheah, Cheah, \& Krausgrill, 1995). Lipid oxidation is the most important chemical alteration of fish flesh postmortem, leading to changes in odour, colour, texture, nutritional value and eventually producing toxic compounds (Baker, 2001; Nunes, Batista, \& Cardoso, 2007). In muscles, lipids are oxidized by chemical compounds or reactive oxygen species that break down the double bonds of phospholipidic fractions of cell membranes. Fish lipids are more susceptible to that reaction because of their high degree of unsaturation (Ruff, Fitzgerald, Cross, Lynch, \& Kerry, 2004). In this study, we used MBs with antioxidant potential in fish feeding to evaluate their effects on blood antioxidant activity, plasmatic biochemistry and flesh quality parameters.

\section{MATERIAL AND METHODS}

\section{1 | Experimental design, animals and blood and flesh sampling}

The procedures cited herein were approved by the Animal Ethics Committee, UNESP (CEUA/FOA 2016/00407). It was adopted a completely randomized design with eight treatments and three replicates, totalizing 960 Nile tilapias (Oreochromis niloticus). Fish averaged $26.84 \pm 1.03 \mathrm{~g}$ and were distributed into 24 tanks (1,000 I) (40 fish/tank, 120 fish per treatment), in a water recirculation system. Experimental diets ( $n=8$, Table 1 ) were provided three times a day, ad libitum, for 76 days. Performance data (initial weight, final weight, weight gain, feed consumption, specific growth rate) were recorded along the trial.

Treatments included a control diet (C), a control diet supplemented with $0.01 \%$ vitamin E (VE), R. gelatinosus at $0.25 \%$ (RG25) or $0.5 \%$ (RG50), S. cerevisiae at $0.25 \%$ (SC25) or $0.5 \%$ (SC50) and S. platensis at $0.25 \%$ (SP25) or $0.5 \%$ (SP50). Vitamin E (Microvit ${ }^{\circledR} \mathrm{E}$ Promix 50) was set at $0.01 \%$ as usual for commercial fish raising. To allow the inclusion of vitamin $\mathrm{E}$ and biomasses in the experimental diets, the following ingredients were partially substituted: ground corn (vitamin E), soya bean meal (S. cerevisiae and S. platensis biomasses) and meat meal ( $R$. gelatinosus biomass). These changes were necessary to make the rations isoproteic and isoenergetic. The calculated and analysed values of the nutrients in the diets are presented in Table 1. R. gelatinosus levels adopted were based on a previous experiment with the biomass in which Santo et al. (2016) reported that its use in fish feed at $0.14 \%$ provided an antioxidant effect on the flesh. So, for the present experiment, we assayed slightly higher levels $(0.25 \%$ and $0.5 \%)$ of that biomass and extended the same concentrations for $S$. cerevisiae and S. platensis. The biomasses contained live cells of the microorganisms and had the following proximal composition: $4 \%$ moisture, $46 \%$ protein, $17 \%$ lipid and $5 \%$ ash for $R$. gelatinosus; $4 \%$ moisture, $45 \%$ protein, $0.2 \%$ lipid and $5 \%$ ash for S. cerevisiae; and $6 \%$ moisture, $46 \%$ protein, $3 \%$ lipid and $8 \%$ ash for S. platensis.

Sediments deposited on the bottom of the tanks were removed by siphoning once a week, and the water quality was monitored twice a week in each tank (temperature $27.0 \pm 0.4^{\circ} \mathrm{C}, \mathrm{pH} 7.0 \pm 0.1$, DO $12.0 \pm 1.0 \mathrm{mg} / \mathrm{l}$, nitrite $0.0016 \pm 0.0002 \mathrm{ppm}, \mathrm{NH}_{3} 0.0038 \pm$ 0.0002 , chloride $0.001 \pm 0.0002$ ). No mortality was observed during the experiment. At the end of the trial, nine fish from each treatment were anaesthetized with benzocaine solution at $0.1 \mathrm{~g} / \mathrm{l}(\mathrm{pH} 7)$ and $0.5-1 \mathrm{ml}$ of blood was collected from the caudal veins in tubes containing sodium heparin. After $24 \mathrm{hr}$ of fasting, the fish were placed on ice and slaughtered by sectioning the gills, and the fillets were removed for the laboratory analyses.

\subsection{Health parameters}

Plasma biochemical analyses were performed in an automated spectrophotometer (BS 200, Shenzhen Mindray Bio-Medical Electronics Co., Nanshan, China) previously calibrated with a calibrator and control reagents (Biosystems, Barcelona, Spain). The levels of the following analytes were determined: total protein (biuret method), albumin (bromocresol green method), globulin ([total protein - albumin]), alanine aminotransferase (ALT, IFCC kinetic method), aspartate aminotransferase (AST, IFCC kinetic method), $\gamma$ glutamyltranspeptidase (GGT, enzymatic UV urease/glutamate dehydrogenase method), alkaline phosphatase (ALP, diethanolamine method), uric acid (uricase/ peroxidase method), creatinine (alkaline picrate kinetic method) and creatine kinase (CK, creatine phosphate method). All the biochemical reactions were performed at $37^{\circ} \mathrm{C}$, following the manufacturer's protocol. The leucocyte respiratory burst was assayed with total blood optical density at $540 \mathrm{~nm}$ following Biller-Takahashi, Takahashi, 
TABLE 1 Basal diet for tilapias

\begin{tabular}{|c|c|c|c|c|c|c|c|c|}
\hline Ingredients (\%) & C & VE & RG25 & RG50 & SC25 & SC50 & SP25 & SP50 \\
\hline Feather meal & 2 & 2 & 2 & 2 & 2 & 2 & 2 & 2 \\
\hline Ground corn & 33.06 & 33.05 & 33.06 & 33.06 & 33.06 & 33.06 & 33.06 & 33.06 \\
\hline Poultry meal by-products & 6 & 6 & 6 & 6 & 6 & 6 & 6 & 6 \\
\hline Soya bean meal & 10.44 & 10.44 & 10.44 & 10.44 & 10.19 & 9.94 & 10.19 & 9.94 \\
\hline Wheat meal & 15.88 & 15.88 & 15.88 & 15.88 & 15.88 & 15.88 & 15.88 & 15.88 \\
\hline Meat meal & 17.14 & 17.14 & 16.89 & 16.64 & 17.14 & 17.14 & 17.14 & 17.14 \\
\hline Blood meal & 12 & 12 & 12 & 12 & 12 & 12 & 12 & 12 \\
\hline $\mathrm{NaCl}$ & 0.8 & 0.8 & 0.8 & 0.8 & 0.8 & 0.8 & 0.8 & 0.8 \\
\hline Chicken oil & 2 & 2 & 2 & 2 & 2 & 2 & 2 & 2 \\
\hline Premix ${ }^{a}$ & 0.6 & 0.6 & 0.6 & 0.6 & 0.6 & 0.6 & 0.6 & 0.6 \\
\hline Methionine & 0.08 & 0.08 & 0.08 & 0.08 & 0.08 & 0.08 & 0.08 & 0.08 \\
\hline Vitamin $\mathrm{E}$ & 0 & 0.01 & 0 & 0 & 0 & 0 & 0 & 0 \\
\hline R. gelatinosus & 0 & 0 & 0.25 & 0.5 & 0 & 0 & 0 & 0 \\
\hline S. cerevisiae & 0 & 0 & 0 & 0 & 0.25 & 0.5 & 0 & 0 \\
\hline S. platensis & 0 & 0 & 0 & 0 & 0 & 0 & 0.25 & 0.5 \\
\hline Total & 100 & 100 & 100 & 100 & 100 & 100 & 100 & 100 \\
\hline \multicolumn{9}{|c|}{ Nutrients/energy - calculated values } \\
\hline Digestible energy $(\mathrm{kcal} / \mathrm{kg})$ & 3,000 & 3,000 & 3,000 & 3,000 & 3,000 & 3,000 & 3,000 & 3,000 \\
\hline Digestible protein (\%) & 27.63 & 27.63 & 27.63 & 27.63 & 27.63 & 27.63 & 27.63 & 27.63 \\
\hline Total protein (\%) & 32.00 & 32.00 & 32.00 & 32.00 & 32.00 & 32.00 & 32.00 & 32.00 \\
\hline Ether extract (\%) & 7.50 & 7.50 & 7.50 & 7.50 & 7.50 & 7.50 & 7.50 & 7.50 \\
\hline Crude fibre (\%) & 3.00 & 3.00 & 3.00 & 3.00 & 3.00 & 3.00 & 3.00 & 3.00 \\
\hline Mineral composition (\%) & 10.48 & 10.48 & 10.48 & 10.48 & 10.48 & 10.48 & 10.48 & 10.48 \\
\hline Total calcium (\%) & 2.74 & 2.74 & 2.74 & 2.74 & 2.74 & 2.74 & 2.74 & 2.74 \\
\hline Total phosphorus (\%) & 1.57 & 1.57 & 1.57 & 1.57 & 1.57 & 1.57 & 1.57 & 1.57 \\
\hline Starch (\%) & 27.03 & 27.03 & 27.03 & 27.03 & 27.03 & 27.03 & 27.03 & 27.03 \\
\hline Available phosphorus (\%) & 0.69 & 0.69 & 0.69 & 0.69 & 0.69 & 0.69 & 0.69 & 0.69 \\
\hline Arginine (\%) & 1.80 & 1.80 & 1.80 & 1.80 & 1.80 & 1.80 & 1.80 & 1.80 \\
\hline Lysine (\%) & 2.33 & 2.33 & 2.33 & 2.33 & 2.33 & 2.33 & 2.33 & 2.33 \\
\hline Threonine (\%) & 1.25 & 1.25 & 1.25 & 1.25 & 1.25 & 1.25 & 1.25 & 1.25 \\
\hline Tryptophan (\%) & 0.34 & 0.34 & 0.34 & 0.34 & 0.34 & 0.34 & 0.34 & 0.34 \\
\hline Methionine (\%) & 0.45 & 0.45 & 0.45 & 0.45 & 0.45 & 0.45 & 0.45 & 0.45 \\
\hline Vitamin C (mg/kg) & 700 & 700 & 700 & 700 & 700 & 700 & 700 & 700 \\
\hline \multicolumn{9}{|l|}{ Nutrients - analysed values (\%) } \\
\hline Protein & 32.29 & 32.18 & 32.26 & 32.39 & 32.26 & 32.22 & 32.41 & 32.34 \\
\hline Ether extract & 8.11 & 8.15 & 8.32 & 8.25 & 8.14 & 8.11 & 8.18 & 8.09 \\
\hline Ash & 9.79 & 9.84 & 9.91 & 9.77 & 9.68 & 9.82 & 9.69 & 9.84 \\
\hline Crude fibre & 3.62 & 3.65 & 3.62 & 3.68 & 3.57 & 3.72 & 3.62 & 3.59 \\
\hline Moisture & 10.75 & 10.63 & 10.79 & 10.82 & 10.65 & 10.85 & 10.93 & 10.86 \\
\hline
\end{tabular}

Notes. C: control diet; VE: control diet supplemented with $0.01 \%$ vitamin E; RG25: control diet supplemented with $0.25 \%$ R. gelatinosus; RG50: control diet supplemented with $0.5 \%$ R. gelatinosus; SC25: control diet supplemented with $0.25 \%$ S. cerevisiae; SC50: control diet supplemented with $0.5 \%$ S. cerevisiae; SP25: control diet supplemented with $0.25 \%$ S. platensis; SP50: control diet supplemented with $0.5 \%$ S. platensis.

${ }^{a}$ Composition per kg of product — choline $83,333 \mathrm{mg}$, vitamin A 2,083 UI, vitamin D3 $500 \mathrm{UI}$, vitamin K3 2,500 mg, vitamin B1 4,167 mg, vitamin B2 4,167 mg, vitamin B6 3,333 mg, vitamin B12 7,500 $\mu \mathrm{g}$, niacin $12,500 \mathrm{mg}$, calcium pantothenate $8,152 \mathrm{mg}$, pantothenic acid $7,500 \mathrm{mg}$, folic acid $833 \mathrm{mg}$, biotin $125 \mathrm{mg}$, vitamin C 116,667 mg, inositol 12,500 mg, iron specific source 12,500 mg, Fe 12,500 mg, Cu 2,500 mg, Mn 7,500 mg, Zn 16,667 mg, Co 42 mg, I 125 mg, Se 67 mg. 
Saita, Gimbo, and Urbinati (2013) methodology, in which the reduction in nitroblue tetrazolium (NBT) is measured according to the production of reactive oxygen species (ROS).

\section{3 | Oxidative stress of the blood}

Plasma TAS and plasma TOS were determined colorimetrically by the reduction in the ABTS cation (2,2'-azino-bis 3-ethylbenzthiazoline-6-sulphonic acid), expressed as mmol Trolox equivalent/ $L$ and by the oxidation of the iron ion, expressed as $\mu \mathrm{mol}$ hydrogen peroxide equivalent/I respectively (Erel, 2004, 2005). Lipid peroxidation was quantified as 2-thiobarbituric acidreactive substances (TBARS) according to Hunter, Nlemadim, and Davidson (1985) and expressed as $\mu \mathrm{mol}$ malonaldehyde (MA).

\section{4 | Lipid oxidation}

Ten grams of fish fillets was homogenized with $50 \mathrm{ml}$ of trichloroacetic acid $7.5 \%$ in turrax, during $1 \mathrm{~min}$. Then, the mixture was filtered and $5 \mathrm{ml}$ of the extract was transferred to a tube containing $5 \mathrm{ml}$ thiobarbituric acid $0.02 \mathrm{M}$. The tubes were heated in a boiling water bath for $40 \mathrm{~min}$ and cooled in running water for $10 \mathrm{~min}$, for the measurement of the 2-thiobarbituric acidreactive substances (TBARS) at $538 \mathrm{~nm}$. The values were expressed as $\mathrm{mg}$ malonaldehyde/ $\mathrm{kg}$. The analyses were performed immediately after slaughter and repeated after 30 and 60 days of storage at $-30^{\circ} \mathrm{C}$.

\subsection{Colour attributes and $\Delta E$}

The CIE colours of fish fillets ( $\mathrm{L}$-lightness, $\mathrm{a}$ - — redness, $\mathrm{b} *$ - yellowness) were obtained in triplicate using a portable MiniScan XE Plus colorimeter (Hunterlab) previously calibrated with white and black standards $\left(10^{\circ}\right.$ observer angle, illuminant D65). Measurements were taken on the inner portion of the muscle above the lateral line, at three points (head, middle and tail), and the mean values were considered (Choubert, Blanc, \& Vallée, 1997). $\Delta E$ was used to classify the colour difference between treatments in categories - distinguishable (1.5-3.0), difficult to distinguish $(<1.5)$ and easily distinguishable $(>3.0$ ) — and was measured as:

$$
\Delta E=\sqrt{\left(\Delta L^{2}\right)+\left(\Delta a^{2}\right)+\left(\Delta b^{2}\right)} .
$$

\section{6 | Carotenoid content}

Prior to the carotenoid extraction, the fish fillets were freeze-dried at $-35^{\circ} \mathrm{C}$ for $48 \mathrm{hr}$ and ground to powder. Then, samples of the lyophilized fillets were vortexed with dimethyl sulfoxide and sonicated for $15 \mathrm{~min}$ at $40^{\circ} \mathrm{C}$. The extraction was performed repeatedly with acetone. The phase separation was attained with diethyl ether and distilled water, and the supernatant was dried with $\mathrm{N}_{2}$. The extract was suspended in acetone for the quantification of total carotenoids were at $475 \mathrm{~nm}$ which were calculated using 2,500 as the coefficient of extinction. The analyses were performed according to Grassi et al. (2016).

\subsection{Statistical analysis}

All data collected were subjected to analysis of variance, and the significant differences between means were checked with Tukey's test $(p<0.05)$. Polynomial regression was used to predict the relationship between redness and carotenoid content on the fillets. The significance level was set at 0.05 .

\section{3 | RESULTS}

The results suggest that supplementing fish feed with $M B$ increased the level of antioxidants in blood and fillets and the flesh colour. Except for the respiratory activity of leucocytes, health parameters were similar among all treatments, indicating that MB supplementation did not impart detrimental effects on renal or hepatic functions and did not pose a health risk for the tilapia. As the initial weight, final weight, weight gain, specific growth rates and feed consumption were the same among the treatments (Table 2), the results presented herein were ascribed to the different diets composition.

\subsection{Health parameters}

The respiratory activity of leucocytes was lower when the tilapias were supplemented with MB, as indicated by lower levels of NBT (Table 3). Plasma biochemical analysis showed no significant differences among the groups (Table 3).

\subsection{Oxidative stress of blood}

Total antioxidant status and TBARS of MB groups were significantly higher and lower (respectively) than control group (Table 3) with no significant differences among them. Except for $S$. cerevisiae, all the other treatments had significantly lower TOS than the control. The lowest TOS values were found in VE, RG50 and SP50.

\section{3 | Lipid oxidation}

Fillets from fish fed MB had a lower lipid oxidation than those fed the control diet, at all times evaluated (Table 4). Among the treatments, there was only a difference between SC25 and SP50 after 60 days of storage, while no significant differences were observed at the other times.

\subsection{Colour attributes, carotenoid content and $\Delta E$}

Except for S. cerevisiae and vitamin E feeds, the colour analysis showed significant differences in the redness between MB diets and the control (Table 5). The highest redness was due to the greater inclusion of $R$. gelatinosus, which differed from all the other 


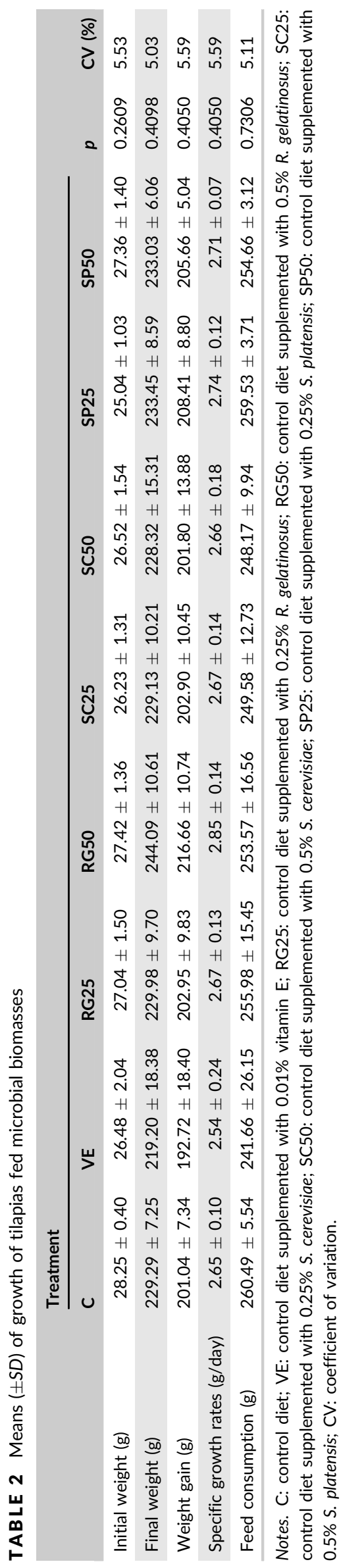

treatments, except for the lower inclusion of $R$. gelatinosus. $L^{*}$ and $b^{*}$ values showed no significant differences among the groups (Table 5). Treatments with R. gelatinosus provided the highest contents of carotenoids in the fillets, followed by the treatments with S. platensis (Table 5). Except for SC25, the MB diets showed distinguishable or easily distinguishable $\Delta E$, compared with the control (Table 6). The polynomial regression analysis showed that the increase in the carotenoids in the fillets explained $88.42 \%$ of the increase on their redness (Figure 1).

\section{DISCUSSION}

\section{1 | Health parameters}

Neutrophils and macrophages are phagocytic cells that generate unpaired oxygen molecules (free radicals) in the presence of antigens (Dügenci, Arda, \& Candan, 2003), causing increases in the NBT measurement. In our study, none of the treatments implied a challenge (no antigens); however, NBT levels in MB tilapia were lower than in control, indicating either that the production of free radicals was decreased or that the antioxidant effect of the biomasses neutralized the free radicals produced by the leucocytes (reducing oxygen radicals and nitrous oxide). So, it is feasible to say that the carotenoids in Rubrivivax and Spirulina (Jaime-Ceballos et al., 2006; Ponsano et al., 2008) and the vitamins in Saccharomyces (Ran et al., 2015) neutralized the free radicals responsible for the reduction in NBT into formazan granules. Free radicals are toxic to microorganisms and host cells because their action is usually unspecific; therefore, they need to be controlled or neutralized in the absence of antigens to protect host cells. Gallani, Valladão, Ponsano, and Pilarski (2017) reported a decreased respiratory activity of leucocytes in pacus (Piaractus mesopotamicus) fed R. gelatinosus biomass. According to Sakai (1999), several components of microorganisms have immunomodulatory activity, which influence the leucocyte respiratory burst. Some authors found enhancement effects on the nonspecific immune response of tilapia fed yeast nucleotides (Xu et al., 2015) and yeast culture (Ran et al., 2015; Zhou et al., 2009).

\subsection{Oxidative stress of blood}

The high TAS and low TOS in the blood of tilapia fed MB demonstrate that the antioxidants of the diets were absorbed and influenced the oxidative metabolism. As dietary antioxidants have been shown to help fight against oxidative stress and immune pathologies (Babin et al., 2015), additives containing carotenoids and vitamins may have positive effects on immunity, acting as a powerful antioxidant and potentially reducing the toxic effects of ROS (Kim, Song, Kim, \& Lee, 2011).

One of the end products of lipid peroxidation is malonaldehyde (MA). Metwally (2009) found that decreasing levels of MA in tilapia given garlic (rich in antioxidants) as compared to a control diet. Antioxidant compounds are thought to inhibit lipoxygenase enzymes, 


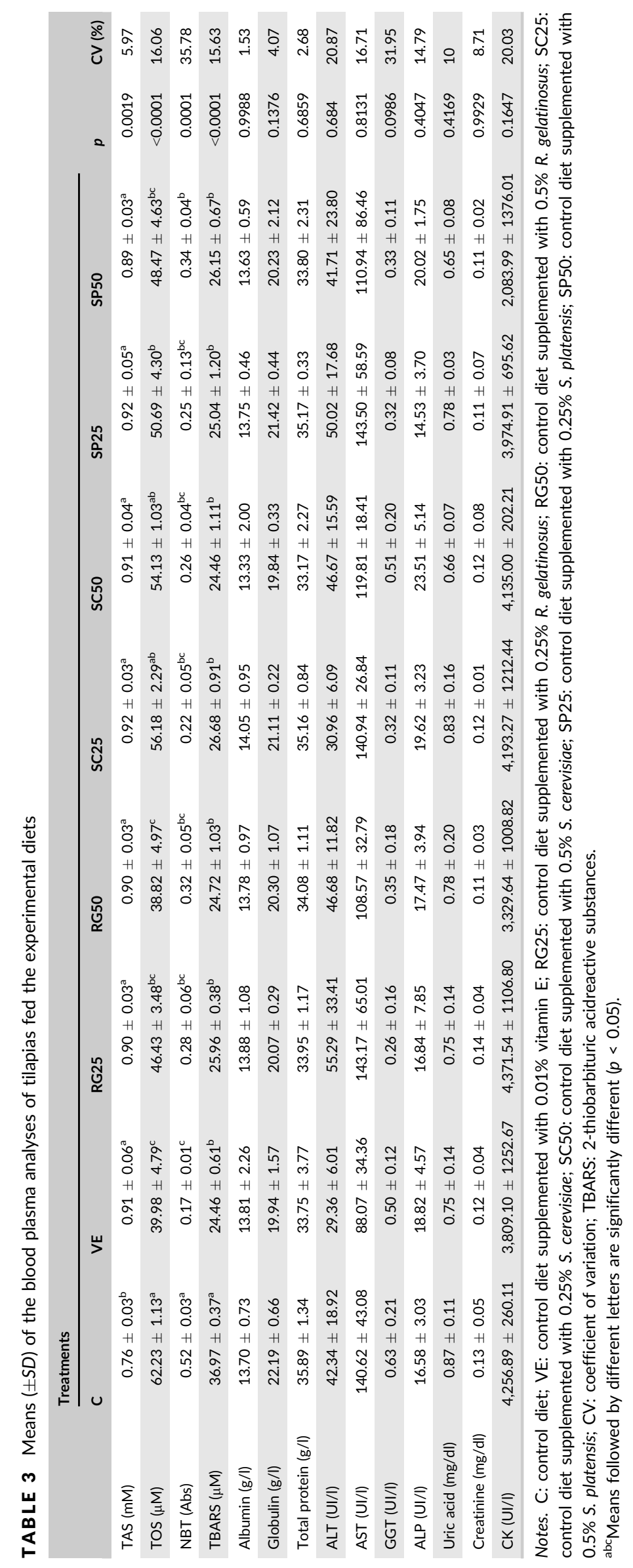



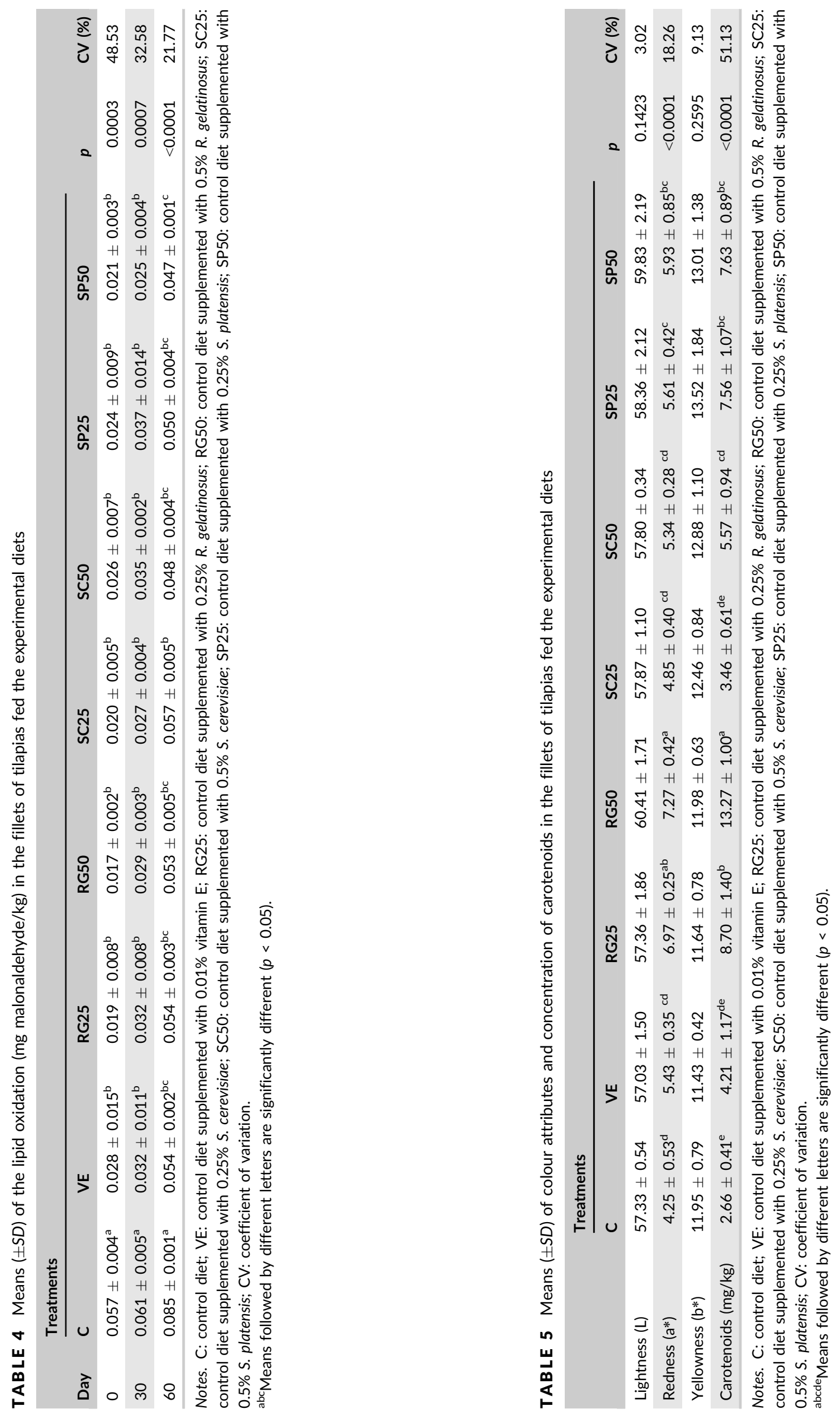
TABLE 6 Human perception for the colours differences on tilapia fillets

\begin{tabular}{|c|c|c|}
\hline \multicolumn{3}{|l|}{$\Delta E$} \\
\hline $\begin{array}{l}\text { Difficult to distinguish } \\
(<1.5)\end{array}$ & $\begin{array}{l}\text { Distinguishable (1.5 } \\
-3.0)\end{array}$ & $\begin{array}{l}\text { Easily distinguishable } \\
(>3.0)\end{array}$ \\
\hline$C-\operatorname{VE}(1.49)$ & C - SC50 (1.51) & C - RG25 (3.04) \\
\hline C - SC25 (0.95) & $C-\mathrm{SP} 25$ (2.22) & $C-$ RG50 (4.11) \\
\hline SC25 - SC50 (0.65) & VE - RG25 (1.71) & C - SP50 (3.19) \\
\hline SC25 - SP25 (1.30) & VE - SC25 (1.53) & VE - RG50 (3.68) \\
\hline \multirow[t]{10}{*}{ SC50 - SP25 (0.86) } & VE - SC50 (1.66) & VE - SP50 (3.23) \\
\hline & VE - SP25 (2.48) & RG25 - RG50 (3.08) \\
\hline & $\mathrm{RG} 25$ - SC25 (2.61) & RG25 - SP50 (3.13) \\
\hline & RG25 - SC50 (2.34) & RG50 - SC25 (3.34) \\
\hline & RG25 - SP25 (2.81) & RG50 - SC50 (3.21) \\
\hline & RG50 - SP25 (2.99) & \\
\hline & RG50 - SP50 (1.57) & \\
\hline & SC25 - SP50 (2.30) & \\
\hline & SC50 - SP50 (2.12) & \\
\hline & SP25 - SP50 (1.63) & \\
\hline
\end{tabular}

Note. C: control diet; VE: control diet supplemented with $0.01 \%$ vitamin E; RG25: control diet supplemented with $0.25 \%$ R. gelatinosus; RG50: control diet supplemented with $0.5 \%$ R. gelatinosus; SC25: control diet supplemented with $0.25 \%$ S. cerevisiae; SC50: control diet supplemented with $0.5 \%$ S. cerevisiae; SP25: control diet supplemented with $0.25 \%$ S. platensis; SP50: control diet supplemented with $0.5 \%$ S. platensis.

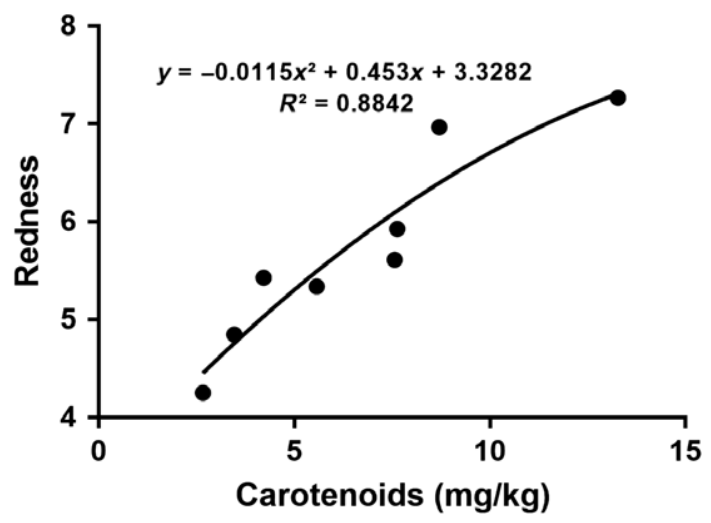

FIGURE 1 Quadratic regression of redness (a*) as a function of the carotenoid content in fillets of tilapias fed the experimental diets

thereby increasing antioxidant capacity and decreasing MA (Schulz, Hansel, Tyler, \& Blumenthal, 2004). Along those lines, Abdelkhalek, Ghazy, and Abdel-Daim (2015) found that MA levels decreased in liver, kidney and brachia of tilapia fed S. platensis and exposed to subacute deltamethrin intoxication, suggesting that $S$. platensis prevents membrane lesions in those organs. Xu et al. (2015) found lower MA level in the liver of juvenile hybrid tilapia fed dietary yeast nucleotides $(0.6 \%$ and $1.2 \%)$, so indicating the enhancement of the antioxidant status.

\section{3 | Lipid oxidation}

Lipid oxidation in the MB fillets was delayed compared with control, at all sampling times, demonstrating the effectiveness of the antioxidant components. The only difference occurred between SC25 and SP50 after 60 days of storage. Santo et al. (2016) reported a lower TBARS in the fillets of tilapia fed $0.14 \%$ R. gelatinosus biomass after 20 days of storage. In our experiment, we also found a lower TBARS in RG25 and RG50 but starting from day 0 , probably because our supplementation levels were higher. Those results were confirmed by the significantly lower levels of TBARS in the blood of tilapia fed R. gelatinosus, along with the high TAS and low TOS, which suggests the existence of an antioxidant effect in vivo that remained postmortem. According to Khan, Bhadouria, and Bisen (2005), in addition to being a source of protein, S. platensis holds antioxidant and immunomodulatory effects (phycocyanin and allophycocyanin), as evidenced by the results of lipid oxidation and NBT respectively. S. cerevisiae also delayed lipid oxidation, suggesting the presence of antioxidants, although they still lack identification. So, it can be said that MB supplementation delayed sensory alterations and the production of substances that pose a risk to human health (aldehydes, ketones, esters, hydrocarbons and other compounds), thereby prolonging the shelf life of fillets, and bringing benefits to consumers and the fish processing industry (Ordoñez, 2005).

\subsection{Colour attributes, carotenoids content and $\Delta E$}

Except for S. cerevisiae, MB supplementation increased redness on the fillets, due to their supply of carotenoids. That was confirmed by the polynomial regression analysis (Figure 1), which assigns $88.4 \%$ of the increase in the fillets redness to the increase in the carotenoids deposited in the muscles. The pigmentation effect of $R$. gelatinosus oxycarotenoids (spiriloxanthin, spheroidene and $\mathrm{OH}$-spheroidene) was previously described by Grassi et al. (2016), who reported mean redness (a*) of 2.55 in the fillets of tilapia fed $0.14 \%$ of that biomass. So, it can be said that increasing the level of $R$. gelatinosus biomass in the diets also increases redness.

Thus, we believe that $R$. gelatinosus biomass should be tested in salmonids as a natural alternative to synthetic pigments (such as astaxanthin and canthaxanthin), which are more costly and, according to Teimouri, Amirkolaie, and Yeganeh (2013) and Ponce-Palafox, Arredondo-Figueroa, and Vernon-Carter (2004), may have negative effects on human health.

Pigmentation effects were also previously assigned to the presence of carotenoids and phycocyanin in S. platensis (Jaime-Ceballos et al., 2006). As found in this study, Teimouri et al. (2013) also reported higher redness in trout fillets fed that biomass. Nevertheless, as S. cerevisiae contains small amounts of carotenoids, no differences were detected for the redness of the SC fillets, when compared to control. According to the DIN 6174 (Deutsche Institut für Normung, 1979), $\Delta E$ is used to detect the colour perception by consumers and, in our study, its measurements revealed that the 
fillets colours were easily distinguishable among MB treatments and control (except for SC25).

\subsection{General considerations}

The utilization of tilapia in this study was justified for the widespread cultivation of this species all over the world. In Brazil, it is fully adapted to the climate (location of experiment) and is the most cultivated species. However, we believe that more experiments should be conducted with other species with the aim of checking whether the positive results found in this study could be extended to others, such as salmonids and shrimps.

\section{5 | CONCLUSION}

From the results found in our study, we concluded that adding MBs to tilapia diets provided antioxidant effects on blood plasma and flesh and increased pigmentation (except for S. cerevisiae) and carotenoid deposition (except for S. cerevisiae at $0.25 \%$ ) in the fillets, without imparting a negative impact on the fish health.

\section{ACKNOWLEDGMENTS}

Authors thank CAPES (88881.134883/2016-01) for the scholarship and FAPESP for the financial support (2015/25853-1) and scholarship (2015/21216-7).

\section{ORCID}

Thiago Luís Magnani Grassi iD http://orcid.org/0000-0003-41092522

\section{REFERENCES}

Abdelkhalek, N. K. M., Ghazy, E. W., \& Abdel-Daim, M. M. (2015). Pharmacodynamic interaction of Spirulina platensis and deltamethrin in freshwater fish Nile tilapia, Oreochromis niloticus: Impact on lipid peroxidation and oxidative stress. Environmental Science and Pollution Research, 22, 3023-3031. https://doi.org/10.1007/s11356-0143578-0

Anesini, C., Ferraro, G., \& Filip, R. (2006). Peroxidase-like activity of Ilex paraguariensis. Food Chemistry, 97, 459-464. https://doi.org/10. 1016/j.foodchem.2005.05.025

Babin, A., Saciat, C., Teixeira, M., Troussard, J. P., Motreuil, S., Moreau, J., \& Moret, Y. (2015). Limiting immunopathology: Interaction between carotenoids and enzymatic antioxidant defences. Developmental \& Comparative Immunology, 49, 278-281. https://doi.org/10.1016/j.dci. 2014.12.007

Baker, R. T. M. (2001). The effect of certain micronutrients on fish flesh quality. In S. C. Kestin, \& P. D. Warris (Eds.), Farmed fish quality (pp. 180-191). Oxford, UK: Blackwell Science.

Baker, R. T. M., Pfeiffer, A. M., Schöner, F. J., \& Smith-Lemmon, L. (2002). Pigmenting efficacy of astaxanthin and canthaxanthin in fresh-water reared Atlantic salmon, Salmo salar. Animal Feed Science and Technology, 99, 97-106. https://doi.org/10.1016/S0377-8401 (02)00116-5
Bhosale, P. (2004). Environmental and cultural stimulants in the production of carotenoids from microorganisms. Applied Microbiology and Biotechnology, 63, 351-361. https://doi.org/10.1007/s00253-0031441-1

Bhosale, P., \& Bernstein, P. S. (2005). Microbial xanthophylls. Applied Microbiology and Biotechnology, 68, 445-455. https://doi.org/10. 1007/s00253-005-0032-8

Biller-Takahashi, J. D., Takahashi, L. S., Saita, M. V., Gimbo, R. Y., \& Urbinati, E. C. (2013). Leukocytes respiratory burst activity as indicator of innate immunity of pacu Piaractus mesopotamicus. Brazilian Journal of Biology, 73, 425-429. https://doi.org/10.1590/S1519-69842013 000200026

Chang, Y., Wu, Z., Bian, L., Feng, D., \& Leung, D. Y. (2013). Cultivation of Spirulina platensis for biomass production and nutrient removal from synthetic human urine. Applied Energy, 102, 427-431. https://doi. org/10.1016/j.apenergy.2012.07.024

Cheah, K. S., Cheah, A. M., \& Krausgrill, D. I. (1995). Effect of dietary supplementation of vitamin $\mathrm{E}$ on pig meat quality. Meat Science, 39, 255-264. https://doi.org/10.1016/0309-1740(94)P1826-H

Choubert, G., Blanc, J. M., \& Vallée, F. (1997). Colour measurement, using the $\mathrm{CIELCH}$ colour space, of muscle of rainbow trout, Oncorhynchus mykiss (Walbaum), fed astaxanthin: Effects of family, ploidy, sex, and location of reading. Aquaculture Research, 28, 15-22. https://doi.org/ 10.1046/j.1365-2109.1997.t01-1-00824.x

Deutsche Institut für Normung (DIN) 6174. (1979). Farbmetrische Bestimmung Von Farbabständen bei Körperfarben nach der CIELAB - Formel. Berlim und Köln: Beuth Verlag.

Dügenci, S. K., Arda, N., \& Candan, A. (2003). Some medicinal plants as immunostimulant for fish. Journal of Ethnopharmacology, 88, 99-106. https://doi.org/10.1016/S0378-8741(03)00182-X

Erel, O. (2004). A novel automated direct measurement method for total antioxidant capacity using a new generation, more stable ABTS radical cation. Clinical Biochemistry, 37, 277-285. https://doi.org/10. 1016/j.clinbiochem.2003.11.015

Erel, O. (2005). A new automated colorimetric method for measuring total oxidant status. Clinical Biochemistry, 38, 1103-1111. https://doi. org/10.1016/j.clinbiochem.2005.08.008

Gallani, S. U., Valladão, G. M. R., Ponsano, E. H. G., \& Pilarski, F. (2017). Rubrivivax gelatinosus biomass as an immunostimulant for pacu Piaractus mesopotamicus. Aquaculture Research, 1-8, https://doi.org/10. 1111/are.13303

Grassi, T. L. M., Santo, E. F. E., Marcos, M. T. S., Cavazzana, J. F., Oliveira, D. L., Bossolani, I. L. C., \& Ponsano, E. H. G. (2016). Bacterial pigment for Nile tilapia feeding. Aquaculture International, 24, 647-660. https://doi.org/10.1007/s10499-015-9955-y

Hamre, K., Christiansen, R., Waagbø, R., Maage, A., Tortensen, B. E., Lygren, B., ... Albrektsen, S. (2004). Antioxidant vitamins, minerals and lipid levels in diets for Atlantic Salmon (Salmo salar, L.): Effects on growth performance and fillet quality. Aquaculture Nutrition, 10, 113-123. https://doi.org/10.1111/j.1365-2095.2003. 00288.x

Herath, S. S., Haga, Y., \& Shuichi, S. (2016). Effects of long-term feeding of corn co-product-based diets on growth, fillet color, and fatty acid and amino acid composition of Nile tilapia, Oreochromis niloticus. Aquaculture, 464, 205-212. https://doi.org/10.1016/j.aquaculture. 2016.06.032

Hou, D. X. (2003). Potential mechanism of cancer chemoprevention by anthocyanin. Current Molecular Medicine, 3, 149-159. https://doi.org/ 10.2174/1566524033361555

Hunter, M. I. S., Nlemadim, B. C., \& Davidson, D. L. W. (1985). Lipid peroxidation products and antioxidant proteins in plasma and cerebrospinal fluid from multiple sclerosis patients. Neurochemical Research, 10, 1645-1652. https://doi.org/10.1007/BF00988606

Jaime-Ceballos, B. J., Hernández-Llamas, A., Garcia-Galiano, T., \& Villarreal, H. (2006). Substitution of Chaetoceros muelleri by Spirulina 
platensis meal in diets for Litopenaeus schmitti larvae. Aquaculture, 260, 215-220. https://doi.org/10.1016/j.aquaculture.2006.06.002

Khan, Z., Bhadouria, P., \& Bisen, P. S. (2005). Nutritional and therapeutic potential of Spirulina. Current Pharmaceutical Biotechnology, 6, 373379. https://doi.org/10.2174/138920105774370607

Kim, S., Song, J., Kim, K., \& Lee, K. (2011). Effects of dietary astaxanthin on innate immunity and disease resistance against Edwardsiella tarda in olive flounder Paralichthys olivaceus. Israeli Journal of Aquaculture, 64, 1-6.

Lara-Flores, M., Olvera-Novoa, M. A., Guzmán-Méndez, B. E., \& LópezMadrid, W. (2003). Use of the bacteria Streptococcus faecium and Lactobacillus acidophilus, and the yeast Saccharomyces cerevisiae as growth promoters in Nile tilapia (Oreochromis niloticus). Aquaculture, 216, 193-201. https://doi.org/10.1016/S0044-8486(02)00277-6

Li, Z. Y., Guo, S. Y., \& Li, L. (2003). Bioeffects of selenite on the growth of Spirulina platensis and its biotransformation. Bioresource Technology, 89, 171-176. https://doi.org/10.1016/s0960-8524(03)00041-5

Lima, L. K. F., Ponsano, E. H. G., \& Pinto, M. F. (2011). Cultivation of Rubrivivax gelatinosus in fish industry effluent for depollution and biomass production. World Journal of Microbiology and Biotechnology, 27, 2553-2558. https://doi.org/10.1007/s11274-011-0725-3

Metwally, M. A. A. (2009). Effects of garlic (Allium sativum) on some antioxidant activities in tilapia nilotica (Oreochromis niloticus). World Journal of Fish and Marine Sciences, 1, 56-64.

Morist, A., Montesimos, J. L., Cusido, J. A., \& Godia, F. (2001). Recovery and treatment of Spirulina platensis cells cultured in a continuous photobioreactor to be used as food. Process Biochemistry, 37, 535547. https://doi.org/10.1016/S0032-9592(01)00230-8

Nunes, M. L., Batista, I., \& Cardoso, C. (2007). Aplicação do índice de qualidade (QIM) na avaliação da frescura do pescado. Lisboa, Portugal: IPIMAR.

Ordoñez, J. A. (2005). Tecnologia de alimentos, 2nd ed.. Porto Alegre, Brazil: Artmed.

Ponce-Palafox, J. T., Arredondo-Figueroa, J. L., \& Vernon-Carter, E. J. (2004). Pigmentation of tilapia (Oreochromis niloticus) with carotenoids from Aztec marigold (Tagetes erecta) in comparison to astaxanthin. Revista Mexicana de Ingeneria Quimica, 3, 219-225.

Ponsano, E. H. G., Lacava, P. M., \& Pinto, M. F. (2003). Chemical composition of Rhodocyclus gelatinosus biomass produced in poultry slaughterhouse wastewater. Brazilian Archives of Biology and Technology, 46, 143-147. https://doi.org/10.1590/S1516-89132003000200001

Ponsano, E. H. G., Paulino, C. Z., \& Pinto, M. F. (2008). Phototrophic growth of Rubrivivax gelatinosus in poultry slaughterhouse wastewater. Bioresource Technology, 99, 3836-3842. https://doi.org/10.1016/ j.biortech.2007.06.063

Ponsano, E. H. G., Pinto, M. F., Garcia Neto, M., \& Lacava, P. M. (2002). Evaluation of Rhodocyclus gelatinosus biomass for broiler pigmentation. Journal of Applied Poultry Research, 11, 77-82. https://doi.org/ 10.1093/japr/11.1.77

Ponsano, E. H. G., Pinto, M. F., Garcia Neto, M., \& Lacava, P. M. (2004). Rhodocyclus gelatinosus biomass for egg yolk pigmentation. Journal of Applied Poultry Research, 13, 421-425. https://doi.org/10.1093/japr/ 13.3.421

Prior, R. L. (2004). Absorption and metabolism of anthocyanins: Potential health effects. Current Molecular Medicine, 3, 149-159. https://doi. org/10.1201/9780203506332.ch1

Ran, C., Huang, L., Liu, Z., Xu, L., Yang, Y., Tacon, P., ... Zhou, Z. (2015). A comparison of the beneficial effects of live and heat-inactivated baker's yeast on Nile Tilapia: Suggestions on the role and function of the secretory metabolites released from yeast. PLoS ONE, 10, e0145448. https://doi.org/10.1371/journal.pone.0145448

Reque, V. R., Moraes, J. R. E., Belo, M. A. A., \& Moraes, F. R. (2010). Inflammation induced by Aeromonas hydrophila in Nile tilapia fed diets supplemented with Saccharomyces cerevisiae. Aquaculture, 300, 37-42. https://doi.org/10.1016/j.aquaculture.2009.12.014

Rodriguez, A., Cuesta, A., Ortuno, J., Esteban, M. A., \& Meseguer, J. (2003). Immunostimulant properties of a cell wall-modified whole Saccharomyces cerevisiae strain administered by diet to seabream (Sparus aurata L.). Veterinary Immunology and Immunopathology, 96, 183-192. https://doi.org/10.1016/j.vetimm.2003.07.001

Ruff, N., Fitzgerald, R. D., Cross, T. F., Lynch, A., \& Kerry, J. P. (2004). Distribution of $\alpha$-tocopherol in fillets of turbot (Scophthalmus maximus) and Atlantic halibut (Hippoglossus hippoglossus), following dietary $\alpha$-tocopheryl acetate supplementation. Aquaculture Nutrition, 10, 7581. https://doi.org/10.1046/j.1365-2095.2003.00280.x/full

Sakai, M. (1999). Current research status of fish immunostimulants. Aquaculture, 172, 63-92. https://doi.org/10.1016/S0044-8486(98)00436-0

Santo, E. F. E., Grassi, T. L. M., Marcos, M. T. S., Oliveira, D. L., Cavazzana, J. F., Ciarlini, P. C., ... Ponsano, E. H. G. (2016). Performance, animal health and fillets quality fed diets supplemented with bacterial biomass. Arquivo Brasileiro de Medicina Veterinária e Zootecnia, 68, 525-534. https://doi.org/10.1590/1678-4162-7979

Schulz, V., Hansel, R., Tyler, V., \& Blumenthal, M. (2004). Rational phytotherapy: A physician's guide. Berlin, Germany: Springer. https://doi. org/10.1007/978-3-662-09666-6

Stahl, W., \& Sies, H. (2003). Antioxidant activity of carotenoids. Molecular Aspects of Medicine, 24, 345-351. https://doi.org/10.1016/S00982997(03)00030-X

Takeuchi, T., Lu, J., Yoshizaki, G., \& Satoh, S. (2002). Effect on the growth and body composition of juvenile tilapia Oreochromis niloticus fed raw Spirulina. Fisheries Science, 68, 34 40. https://doi.org/10. 1046/j.1444-2906.2002.00386.x

Teimouri, M., Amirkolaie, A. K., \& Yeganeh, S. (2013). The effects of Spirulina platensis meal as a feed supplement on growth performance and pigmentation of rainbow trout (Oncorhynchus mykiss). Aquaculture, 396-399, 14-19. https://doi.org/10.1016/j.aquaculture.2013.02.009

Xu, L., Ran, C., He, S., Zhang, J., Hu, J., Yang, Y., ... Zhou, Z. (2015). Effects of dietary yeast nucleotides on growth, non-specific immunity, intestine growth and intestinal microbiota of juvenile hybrid tilapia Oreochromis niloticus $\$ \times$ Oreochromis aureus ơ'. Animal Nutrition, 1, 244-251. https://doi.org/10.1016/j.aninu.2015.08.006

Zhou, Z., He, S., Liu, Y., Shi, P., Huang, G., \& Yao, B. (2009). The effects of dietary yeast culture or short-chain fructo-oligosaccharides on the intestinal autochthonous bacterial communities in juvenile hybrid tilapia, Oreochromis niloticus $\$ \times$ Oreochromis aureus $\sigma^{\prime \prime}$. Journal of the World Aquaculture Society, 40, 450-459. https://doi.org/10.1111/j. 1749-7345.2009.00272.x

How to cite this article: Grassi TLM, Oliveira DL, Paiva NM, et al. Microbial biomass as an antioxidant for tilapia feed. Aquac Res. 2018;00:1-10. https://doi.org/10.1111/are.13753 